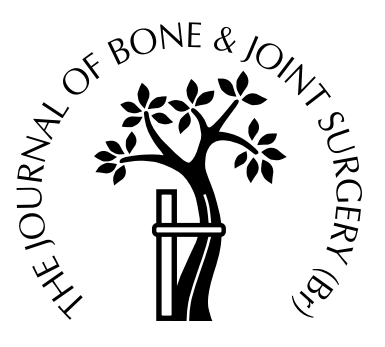

\title{
Medium-term results of percutaneous, arthroscopically-assisted osteosynthesis of fractures of the tibial plateau
}

\author{
T. Scheerlinck, C. S. Ng, F. Handelberg, P. P. Casteleyn \\ From the Academic Hospital, Free University of Brussels, Belgium
}

W e carried out percutaneous, arthroscopicallyand fluoroscopically-assisted osteosynthesis of fractures of the tibial plateau in 52 patients, of whom 38 were assessed using the HSS knee score and standing radiographs. We reviewed 31 AO type-B fractures and seven type-C fractures after a mean follow-up of five years (1 to 14). Fixation was achieved using percutaneous screws and/or an external frame; 33 associated intra-articular injuries, diagnosed in 21 out of the 38 patients, were treated arthroscopically.

Subjectively, $94.7 \%$ of the patients reviewed were satisfied. According to the HSS knee score $78.9 \%$ of the results were excellent, $13.2 \%$ good, $7.9 \%$ fair and none was poor. Narrowing of the joint space was found in $28.9 \%$ of the injured and $5.3 \%$ of the unaffected knees and axial deviation of $5^{\circ}$ to $10^{\circ}$ in $15.8 \%$ of the injured and $10.5 \%$ of the unaffected knees.

Of the 52 fractures, reduction was incomplete in one, and in two secondary displacement occurred, of which one required corrective osteotomy. Deep-venous thrombosis occurred in four cases.

The technique has proved to be safe but demanding. It facilitates diagnosis and appropriate treatment of associated intra-articular lesions.

J Bone Joint Surg [Br] 1998;80-B:959-64.

Received 30 December 1997; Accepted after revision 30 April 1998

In fractures of the tibial plateau precise reduction of the articular surface with stable fixation restores the mechanical axis allowing early mobilisation. Ligamentous stability and preservation of the menisci are important for a longlasting result. ${ }^{1-9}$ Open reduction and internal fixation has a

T. Scheerlinck, MD, Resident

C. S. Ng, MD, Resident

F. Handelberg, MD, Associate Clinical Professor

P. P. Casteleyn, MD, Professor

Department of Orthopaedics and Traumatology, Academic Hospital of the

Free University of Brussels, 1090 Brussels, Laarbeeklaan 101, Belgium.

Correspondence should be sent to Dr T. Scheerlinck.

(C)1998 British Editorial Society of Bone and Joint Surgery 0301-620X/98/68687\$2.00

VOL. 80-B, No. 6, NOVEMBER 1998 significant complication rate $8,10,11$ which has encouraged interest in percutaneous techniques. ${ }^{12-15}$ Arthroscopy is particularly helpful since it provides a good view of the fractured articular surface and any other intra-articular lesion, while limiting soft-tissue damage. Good early results of arthroscopically-assisted osteosynthesis of fractures of the tibial plateau have been reported previous1y. ${ }^{16-23}$ There are few long-term studies. Our aim was to determine whether the good immediate results withstood the test of time.

\section{Patients and Methods}

We performed arthroscopically-assisted treatment in 64 patients with fracture of the proximal tibia involving the knee. In seven the intercondylar eminence had been avulsed in a single injury; they were excluded because they represented an isolated injury to the cruciate ligament. Another five patients were treated conservatively after arthroscopic evaluation and were also excluded. In the 52 remaining patients the fractures were reduced percutaneously and fixed under arthroscopic and fluoroscopic control by one of the senior authors (FH or PPC).

There were 38 patients, 22 women and 16 men with a mean age at injury of 47 years (14 to 81 ), available for independent review (TS or CSN). One patient had died from an unrelated cause and 13 others could not be traced or refused to participate in the study. These lost patients were assessed from their hospital records but, since their follow-up was for less than one year, only information about the fracture, complications and the early results are described. The mean follow-up was 5.2 years (1.3 to 14 ); 21 of the patients reviewed had a follow-up of five years or more.

Using the AO classification ${ }^{24}$ there were 44 unicondylar type-B and eight bicondylar type-C fractures. The types of fracture and method of osteosynthesis in all 52 patients are shown in Table I. Arthroscopy enabled us to diagnose 44 associated intra-articular lesions in 28 patients (Table II). Meniscal tears were resected in 12 patients, sutured in two and left alone in two. One displaced fracture of the intercondylar eminence was fixed during the same operation, but ruptures of the anterior cruciate ligament (ACL) were not repaired or reconstructed. Three patients had sustained 
Table I. The AO-fracture type and method of osteosynthesis used in the 38 patients available for review and the 14 lost to follow-up

\begin{tabular}{|c|c|c|c|c|}
\hline \multirow[b]{2}{*}{ AO-fracture type } & \multicolumn{4}{|c|}{ Number of patients } \\
\hline & $\begin{array}{l}\text { Screw } \\
\text { fixation alone }\end{array}$ & $\begin{array}{l}\text { External } \\
\text { fixation alone }\end{array}$ & $\begin{array}{l}\text { Screw + } \\
\text { external fixation }\end{array}$ & Total \\
\hline \multicolumn{5}{|l|}{ B1 Total } \\
\hline Reviewed & $12 *+3 \dagger$ & 0 & 0 & 15 \\
\hline Lost to follow-up & $2 *+3 \dagger$ & 0 & $1 \dagger$ & 6 \\
\hline \multicolumn{5}{|l|}{ B2 Total } \\
\hline Reviewed & $9 *$ & 0 & 0 & 9 \\
\hline Lost to follow-up & $3 *+1 \dagger$ & 0 & 0 & 4 \\
\hline \multicolumn{5}{|l|}{ B3 Total } \\
\hline Reviewed & $4^{*}+1 \dagger$ & $1 *$ & $1 *$ & 7 \\
\hline Lost to follow-up & $3 *$ & 0 & 0 & 3 \\
\hline \multicolumn{5}{|l|}{ C1 Total } \\
\hline Reviewed & 1 & 0 & 3 & 4 \\
\hline Lost to follow-up & 0 & 0 & 0 & 0 \\
\hline \multicolumn{5}{|l|}{ C2 Total } \\
\hline Reviewed & 0 & 1 & 1 & 2 \\
\hline Lost to follow-up & 0 & 0 & 0 & 0 \\
\hline \multicolumn{5}{|l|}{ C3 Total } \\
\hline Reviewed & 0 & 0 & 1 & 1 \\
\hline Lost to follow-up & 0 & 1 & 0 & 1 \\
\hline \multicolumn{5}{|l|}{ Total } \\
\hline Reviewed & 30 & 2 & 6 & 38 \\
\hline Lost to follow-up & 12 & 1 & 1 & 14 \\
\hline
\end{tabular}

Table II. Associated intra-articular lesions in 21 of the patients reviewed and in seven of those lost to follow-up

\begin{tabular}{lcc}
\hline & \multicolumn{2}{l}{ Number of lesions } \\
\cline { 2 - 3 } & Reviewed & Lost to follow-up \\
\hline Lateral meniscal lesion & 9 & 2 \\
Medial meniscal lesion & 3 & 2 \\
Fracture of the intercondylar eminence & 3 & 1 \\
ACL: haematoma/partial rupture & 7 & 3 \\
ACL: complete rupture & 2 & 1 \\
PCL* injury & 3 & 0 \\
Collateral ligament injury & 3 & 0 \\
Articular cartilage lesion & 3 & 2 \\
Total & 33 & 11 \\
Number of patients involved & 21 & 7 \\
\hline
\end{tabular}

* posterior cruciate ligament a severe injury to the medial collateral ligament which was confirmed arthroscopically. These lesions were treated conservatively.

Percutaneous reduction of the fracture and osteosynthesis were performed under fluoroscopic and arthroscopic control. According to the type of fracture and size of the fragment 6.5-AO cannulated screws, 6.5-AO spongiosa screws, large cannulated Herbert screws or Kirschner wires were used. Metaphyseal or unstable fractures needed additional external fixation (Figs 1 to 3). Split fractures were reduced by closed manipulation together with percutaneous pinning by the joy-stick technique (Fig. 4). Depressed fractures were elevated through a cortical win-

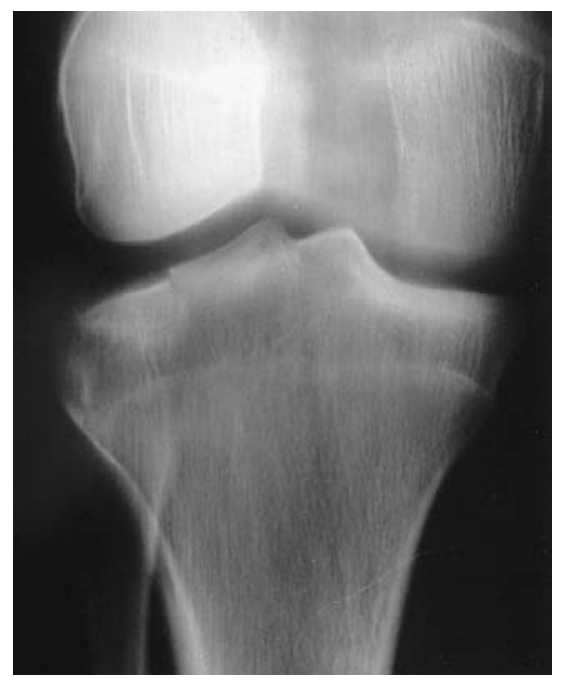

Fig. 1a

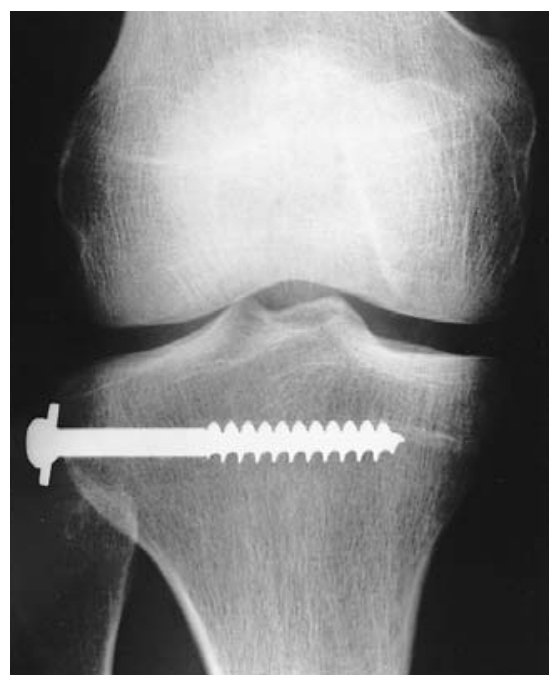

Fig. 1b
Radiographs showing a) a depressed type-B2 fracture of the lateral tibial plateau and b) arthroscopically-controlled elevation and stabilisation of the fracture with a percutaneous $\mathrm{AO}$ spongiosa screw without supplementary bone grafting. 


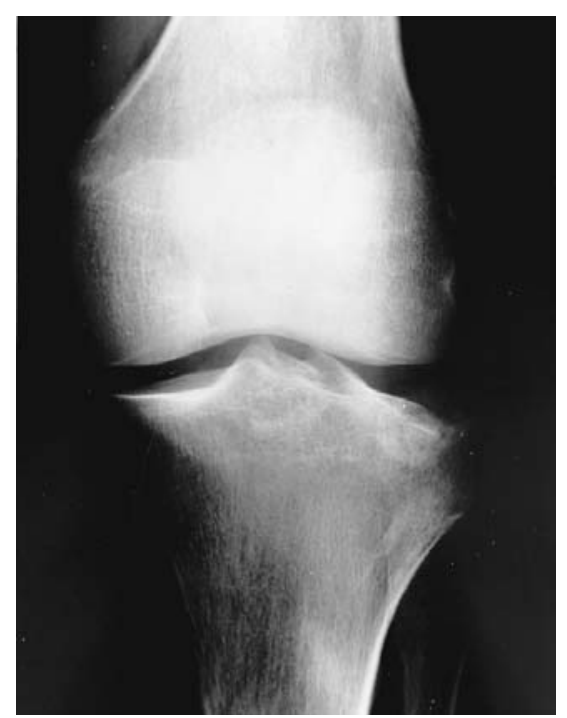

Fig. 2a

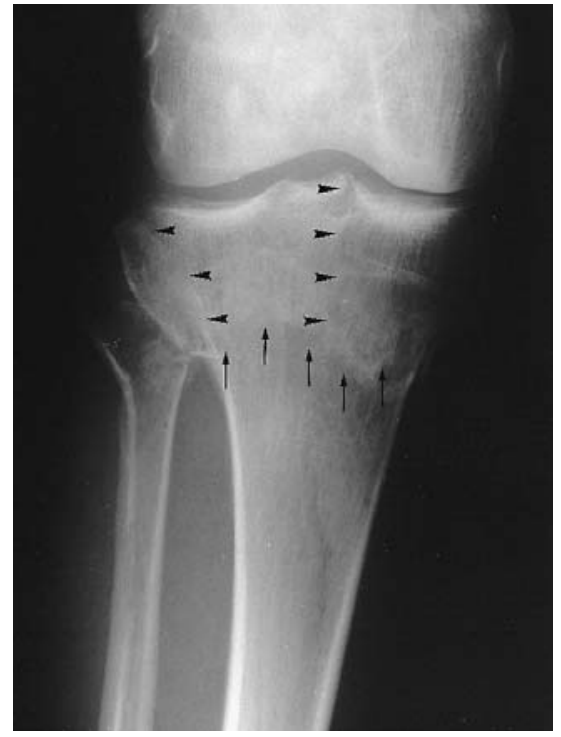

Fig. 3a

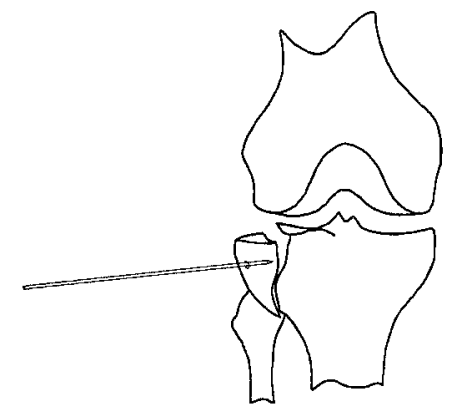

a

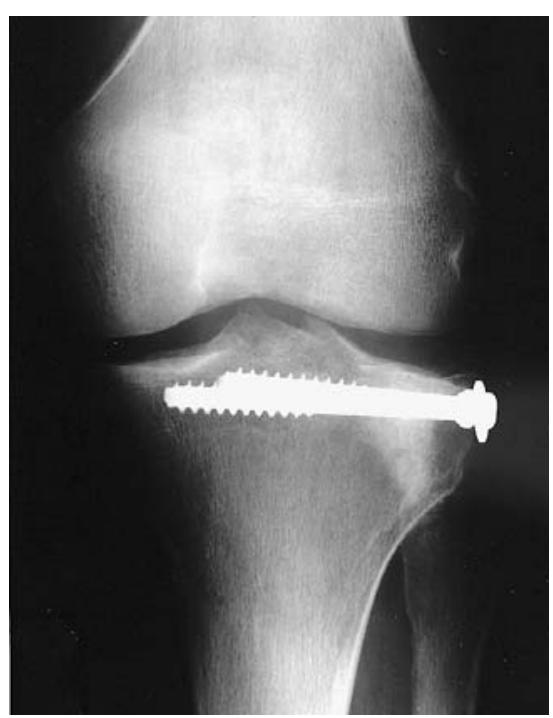

Fig. $2 b$

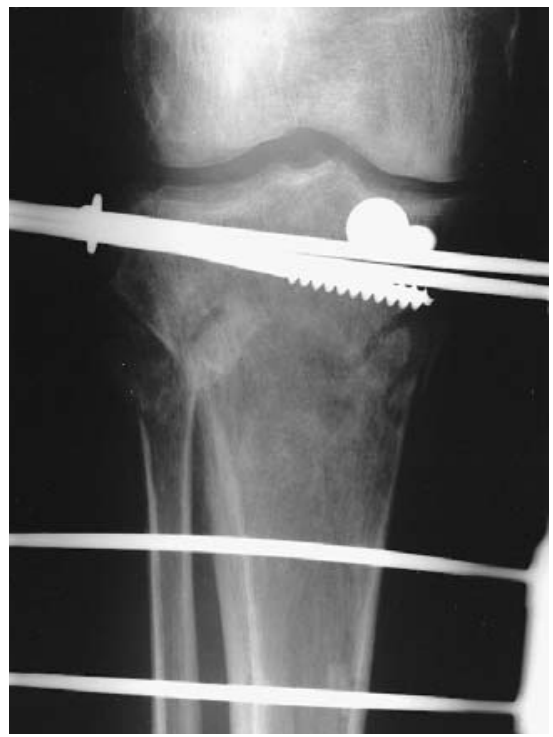

Fig. 3b

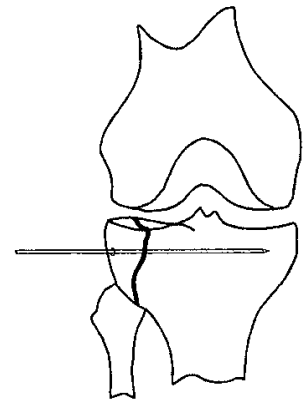

b
Figure 2 - Radiographs showing a) a split depressed type-B3 fracture of the lateral tibial plateau and $b$ ) fracture elevation and bone grafting under arthroscopic control, with percutaneous stabilisation using two cannulated screws.

Figure 3 - Radiographs showing a) a bicondylar type-C1 fracture of the tibial plateau and b) arthroscopically-controlled percutaneous osteosynthesis of both tibial plateaux with two AO screws and reduction of the metaphyseal fracture with an $\mathrm{AO}$ external fixation frame.

\section{Fig. 4}

Diagrams showing the joy-stick technique for fixation of split fractures. A Kirschner wire is introduced into one of the larger fragments to facilitate manipulation (a). When an adequate position is found, the wire is advanced into the major fragment (b). With arthroscopic visualisation of the articular surface, a cannulated screw is run over the wire and the fracture compressed (c). 

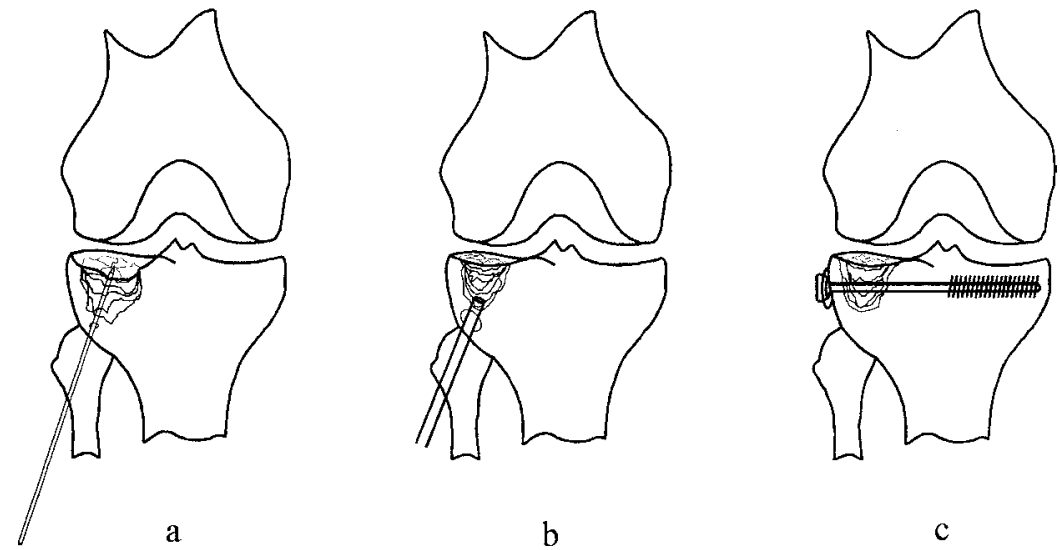

Fig. 5

Diagrams showing the technique for fixation of depressed fractures. A cortical window is prepared beneath the depressed articular surface. The exact location and direction of the window are found by positioning, under arthroscopic control, an ACL tibial guide above the most depressed part of the tibial plateau. A Kirschner wire (a) and subsequently a cannulated drill are used to make a tunnel through which a punch is introduced and bone graft is impacted (b). A screw is advanced into the subchondral bone, parallel to the articular surface, to stabilise the fracture $(\mathrm{c})$

dow (Fig. 5). Bone grafting was carried out in nine of the fractures reviewed and in four not available for follow-up. A pneumatic tourniquet was used routinely. During arthroscopy, the pressure of the intra-articular fluid was kept below $40 \mathrm{mmHg}$. The mean time for anaesthesia was 88 minutes (35 to 205). All patients were mobilised immediately after surgery, using continuous passive motion. Weight-bearing was delayed until there was radiological evidence of healing of the fracture, generally at about three months.

Patients were assessed clinically using the Hospital for Special Surgery (HSS) Knee Score ${ }^{25}$ and radiologically using weight-bearing bipedal and long-leg films. Osteoarthritic changes were judged according to the scale of Ahlbäck ${ }^{26}$ and the mechanical axis was measured on the radiographs.

\section{Results}

According to the HSS knee score 30 patients were rated as excellent (100 to 85 ), five good (84 to 70), three fair (69 to $60)$ and none poor $(<60)$. The relationship between the HSS knee score, the type of fracture and associated intra-articular injuries is shown in Table III. All but one of the patients lost to follow-up, had a satisfactory result at their last visit. The exception had an incomplete reduction of the fracture and a poor result was predicted. None of the patients lost to follow-up was re-operated on in our hospital, except for two who had metal implants removed as a late elective procedure.

At late review, 11 patients had radiological signs of degenerative arthritis of the injured knee as indicated by narrowing of the joint space on weight-bearing radiographs, but two had similar signs in the contralateral unaffected knee. No severe osteoarthritis with complete loss of joint space or bone destruction was observed. Axial deviation of between 5 and $10^{\circ}$, measured on long-leg standing radiographs, was found in six of the affected knees and four of those unaffected.

Subjectively, 36 of the reviewed patients were very pleased with the treatment, two were only mildly satisfied and none was dissatisfied. Work or sporting activities were adversely affected to a minor degree (Table IV), although not all patients were working or participating in sport before injury. At follow-up 31 of the 38 patients took no analgesics, three took them less than once a week and four more often.

Table III. HSS knee score according to associated intra-articular lesions in 21 patients and fracture type in the 38 patients reviewed

\begin{tabular}{lllll}
\hline & \multicolumn{2}{l}{ HSS score } & & \\
\cline { 2 - 4 } & $\begin{array}{l}\text { Excellent } \\
\mathbf{( 1 0 0} \text { to } \mathbf{8 5})\end{array}$ & $\begin{array}{l}\text { Good } \\
\mathbf{( 8 4} \text { to } \mathbf{7 0})\end{array}$ & $\begin{array}{l}\text { Fair } \\
\mathbf{( 6 9} \text { to 60) }\end{array}$ & Total \\
\hline $\begin{array}{l}\text { Associated intra- } \\
\text { articular lesions }\end{array}$ & 18 & 2 & 1 & 21 \\
$\begin{array}{l}\text { Fracture type } \\
\text { B1 }\end{array}$ & $10^{*}+1 \dagger$ & $1^{*}+2 \dagger$ & $1^{*}$ & 15 \\
B2 & $8^{*}$ & $1^{*}$ & 0 & 9 \\
B3 & $6^{*}+1 \dagger$ & 0 & 0 & 7 \\
C1 & 2 & 1 & 1 & 4 \\
C2 & 2 & 0 & 0 & 2 \\
C3 & 0 & 0 & 1 & 1 \\
Total & $30(78.9 \%)$ & $5(13.2 \%)$ & $3(7.9 \%)$ & 38 \\
\hline
\end{tabular}

* lateral tibial plateau

$\dagger$ medial tibial plateau

Table IV. Effect of knee injury on work and sports activity in the 38 patients reviewed, by number and percentage

\begin{tabular}{llll}
\hline & Not affected & Had to adapt & Severely impaired \\
\hline Work & $28(73.7)$ & $6(15.8)$ & $4(10.5)$ \\
Sports & $24(63.1)$ & $8(21.1)$ & $6(15.8)$ \\
\hline
\end{tabular}


There were no complications directly associated with the arthroscopy in any of the 52 patients. Two of those reviewed who were initially treated by external fixation and percutaneous screws, sustained a secondary displacement of a condylar fracture; one of them eventually needed a tibial osteotomy. Deep-venous thrombosis occurred in four patients, and one knee had to be manipulated under anaesthesia six months after the injury to achieve an acceptable range of movement.

\section{Discussion}

Fractures of the tibial plateau require anatomical reduction and stable fixation in order to begin mobilisation early. This is further facilitated if soft-tissue damage can be kept to a minimum. Arthroscopic percutaneous techniques have given favourable short-term results ${ }^{16-21}$ and our study indicates similar findings after medium-term follow-up.

According to the HSS knee score, 79\% of reviewed patients had an excellent functional result at a mean followup of five years. This is substantiated by the low incidence of functional limitations at work and sport, and the high satisfaction rate. Unicondylar fractures tend to achieve better results than bicondylar fractures. In our series $83.9 \%$ of type-B fractures had excellent results compared with $57.1 \%$ of type-C injuries. Similar conclusions were reached by Moore et $\mathrm{al}^{11}$ studying a larger population treated by traction or open osteosynthesis. Impaction or combined split impaction fractures (types B2 and B3) gave excellent results in $93.3 \%$ and had a slightly better prognosis than pure split fractures (73.3\% with excellent results). This is at variance with the findings of Moore et al. ${ }^{11}$

Associated intra-articular injuries were found in $53.8 \%$ of our series. A similar high incidence has been observed previously. ${ }^{22,23,27}$ Diagnosis and immediate treatment of most associated lesions can be carried out at arthroscopy which accounts for the observations that such injuries did not seem to play a major role in the final functional outcome of the patients reviewed (Table III). In contrast to Burchko and Johnson ${ }^{19}$ we believe that immediate ACL reconstruction should not be attempted since it represents a significant supplementary injury to a knee that has already been severely injured. We treated these lesions conservatively. Out of nine patients with a partial or complete rupture of the ACL, eight achieved an excellent result (HSS score 100 to 85 ) and none of the patients reviewed required a secondary reconstruction of this ligament. Fractures of the intercondylar eminence associated with those of the tibial plateau were reduced and fixed immediately when unstable. Delamarter, Hohl and Hopp ${ }^{28}$ reported severe associated injuries of the collateral ligament in $21 \%$ of their patients, based on operative findings and stress films; we found an incidence of only 5.8\% arthroscopically. These lesions were also treated conservatively with satisfactory results.

Radiologically, $28.9 \%$ of the knees reviewed showed narrowing of the joint space on standing films at a mean follow-up of five years. This is less than the $64 \%$ reported by Honkonen ${ }^{3}$ after open osteosynthesis of the tibial plateau at a mean follow-up of 7.6 years. This discrepancy could be explained by differences in the type of fracture, the high prevalence of osteoarthritis in the uninjured knee (33\% compared with 5\% in our series) and the high incidence of total meniscectomy in his series (35.5\%). As advocated by others, ${ }^{22,23,27}$ we performed arthroscopic meniscal fixation or minimal resection whenever possible. This may account for the lower incidence of degenerative changes in our series. ${ }^{3,29} \mathrm{Hohl}^{6}$ reported a large study of fractures of the tibial plateau treated by a variety of conservative and operative techniques, including arthroscopy, resulting in an incidence of "osteoarthrosis" of $21 \%$ after six years. The term osteoarthrosis is not properly defined and axial deformity of more than $10^{\circ}$ was found in $28 \%$ of the cases compared with only 5 to $10^{\circ}$ of malalignment in $15.8 \%$ of our patients.

Secondary displacement of a condylar fracture occurred twice in type-C fractures treated by percutaneous osteosynthesis and an additional AO external fixation frame. This suggests that the AO frame may not be effective in stabilising comminuted metaphyseal fractures; the use of a semicircular frame as suggested by Mallik et $\mathrm{al}^{12}$ could be an alternative. Deep-venous thrombosis was detected in four patients $(7.7 \%)$ which is a higher incidence than has been reported in the literature for elective knee arthroscopy $(0.17 \%$ to $4.2 \%)$ but lower than that for general knee surgery (25\% to $57 \%$ ). ${ }^{30,31}$ Fluid extrusion or bleeding was suppressed by the use of a low irrigation pressure in combination with a tourniquet. No deep sepsis or severe pin-track infection was noted which may be attributable to the percutaneous technique, especially in bicondylar fractures in which rates of infection of $23 \%$ or more have been recorded after open osteosynthesis. ${ }^{10,11}$ Technical difficulties require experience and may result in longer operation times than with open techniques, but this should not be considered a disadvantage.

No benefits in any form have been received or will be received from a commercial party related directly or indirectly to the subject of this article.

\section{References}

1. Lansinger O, Bergman B, Körner L, Anderson GBJ. Tibial condylar fractures: a 20-year follow-up. J Bone Joint Surg [Am] 1986; 68-A:13-9.

2. Honkonen SE. Indications for surgical treatment of tibial condyle fractures. Clin Orthop 1994;302:199-205.

3. Honkonen SE. Degenerative arthritis after tibial plateau fractures. J Orthop Trauma 1995;9:273-7.

4. Volpin G, Dowd GS, Stein H, Bentley G. Degenerative arthritis after intra-articular fractures of the knee: long-term results. J Bone Joint Surg [Br] 1990;72-B:634-8.

5. Gausewitz S, Hohl M. The significance of early motion in the treatment of tibial plateau fractures. Clin Orthop 1986;202:135-8.

6. Hohl M. Managing the challenge of tibial plateau fractures. J Musculoskel Med 1991;8:70-86.

7. Waddell JP, Johnston DWC, Neidre A. Fractures of the tibial plateau: a review of 95 patients and comparison of treatment methods. J Trauma 1981;21:376-81.

8. Schatzker J, McBroom R, Bruce D. The tibial plateau fracture: the Toronto experience 1968-1975. Clin Orthop 1979;138:94-104. 
9. Delamarter R, Hohl M. The cast brace and tibial plateau fractures. Clin Orthop 1989;242:26-31.

10. Young MJ, Barrack RL. Complications of internal fixation of tibial plateau fractures. Orthop Rev 1994;23:149-54.

11. Moore TM, Patzakis MJ, Harvey JP. Tibial plateau fractures: definition, demographics, treatment rationale, and long-term results of closed traction management or operative reduction. J Orthop Trauma 1987;1:97-119.

12. Mallik AR, Covall DJ, Whitelaw GP. Internal versus external fixation of bicondylar tibial plateau fractures. Orthop Rev 1992; 21:1433-6.

13. Keogh P, Kelly C, Cashman WF, McGuinness AJ, O'Rourke SK. Percutaneous screw fixation of tibial plateau fractures. Injury 1992; 23:387-9.

14. Harper MC, Henstorf JE, Vessely MB, Maurizi MG, Allen WC. Closed reduction and percutaneous stabilization of tibial plateau fractures. Orthopedics 1995;18:623-6.

15. Koval KJ, Sanders R, Borrelli J, et al. Indirect reduction and percutaneous screw fixation of displaced tibial plateau fractures. J Orthop Trauma 1992;6:340-6.

16. Holzach P, Matter P, Minter J. Arthroscopically assisted treatment of lateral tibial plateau fractures in skiers: use of a cannulated reduction system. J Orthop Trauma 1994;8:273-81.

17. Jennings JE. Arthroscopic management of tibial plateau fractures. Arthroscopy 1985;1:160-8.

18. Fowble CD, Zimmer JW, Schepsis AA. The role of arthroscopy in the assessment and treatment of tibial plateau fractures. Arthroscopy 1993;9:584-90.

19. Buchko GM, Johnson DH. Arthroscopy assisted operative management of tibial plateau fractures. Clin Orthop 1996;332:29-36.
20. Handelberg F, Casteleyn P-P, DeRoeck P. Arthroscopic assessment and treatment of tibial plateau fractures. Arthroscopy 1991;7:318.

21. Wallenbock F, Ledinski C. Indications and limits of arthroscopic management of intra-articular fractures of the knee joint. Aktuelle Traumatol 1993;23:97-101.

22. Bernfeld B, Kligman M, Roffman M. Arthroscopic assistance for unselected tibial plateau fractures. Arthroscopy 1996;12:598-602.

23. Caspari RB, Hutton PM, Whipple TL, Meyers JF. The role of arthroscopy in the management of tibial plateau fractures. Arthroscopy 1985;1:76-82.

24. Müller ME, Nazarian $\mathbf{S}$, Koch $\mathbf{P}$, Schatzker J. The comprehensive classification of fractures of long bones. Berlin, etc; Springer-Verlag, 1990.

25. Ranawat CS, Shine JJ. Duo-condylar total knee arthroplasty. Clin Orthop 1973;94:185-95.

26. Ahlbäck S. Osteoarthrosis of the knee: a radiographic investigation. Acta Radiol 1968;Suppl 277:7-72.

27. Vangsness CT Jr, Ghaderi B, Hohl M, Moore TM. Arthroscopy of meniscal injuries with tibial plateau fractures. J Bone Joint Surg [Br] 1994;76-B:488-90.

28. Delamarter RB, Hohl M, Hopp E Jr. Ligament injuries associated with tibial plateau fractures. Clin Orthop 1990;250:226-33.

29. Jensen DB, Rude C, Duus B, Bjerg-Nielsen A. Tibial plateau fractures: a comparison of conservative and surgical treatment. J Bone Joint Surg [Br] 1990;72-B:49-52.

30. Stringer MD, Steadman CA, Hedges AR, et al. Deep vein thrombosis after elective knee surgery: an incidence study in 312 patients. J Bone Joint Surg [Br] 1989;71-B:492-7.

31. Williams JS, Hulstyn MJ, Fadale PD, et al. Incidence of deep vein thrombosis after arthroscopic knee surgery: a prospective study. Arthroscopy 1995;11:701-5. 